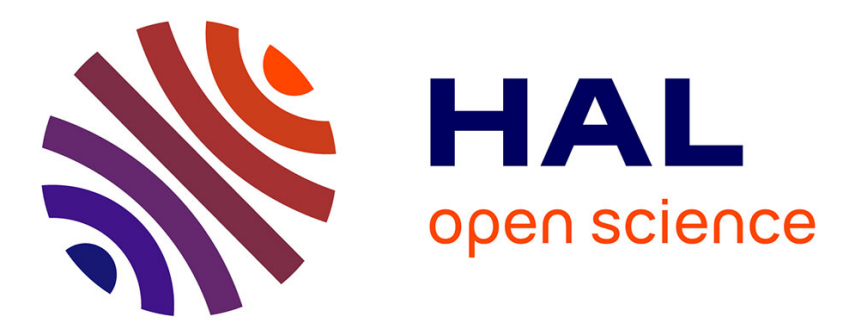

\title{
Optimal Group Incentives with Social Preferences and Self-Selection
}

\author{
Sabrina Teyssier
}

\section{To cite this version:}

Sabrina Teyssier. Optimal Group Incentives with Social Preferences and Self-Selection. 2007. halshs00144901

\section{HAL Id: halshs-00144901 https://shs.hal.science/halshs-00144901}

Submitted on 7 May 2007

HAL is a multi-disciplinary open access archive for the deposit and dissemination of scientific research documents, whether they are published or not. The documents may come from teaching and research institutions in France or abroad, or from public or private research centers.
L'archive ouverte pluridisciplinaire HAL, est destinée au dépôt et à la diffusion de documents scientifiques de niveau recherche, publiés ou non, émanant des établissements d'enseignement et de recherche français ou étrangers, des laboratoires publics ou privés. 


\section{Optimal Group Incentives with Social Preferences and Self-Selection}

Sabrina Teyssier

Avril 2007

GATE Groupe d'Analyse et de Théorie Économique UMR 5824 du CNRS

93 chemin des Mouilles - 69130 Écully - France

B.P. 167 - 69131 Écully Cedex

Tél. +33 (0)4 72866060 - Fax +33 (0)4 72866090

Messagerie électronique gate@gate.cnrs.fr

Serveur Web : www.gate.cnrs.fr 


\title{
Optimal Group Incentives with
}

\section{Social Preferences and Self-Selection*}

\author{
Sabrina Teyssier ${ }^{\dagger}$
}

April 2007

\begin{abstract}
In this paper, we analyze group incentives when a proportion of agents feel inequity aversion as defined by Fehr and Schmidt (1999). We define a separating equilibrium that explains the co-existence of multiple payment schemes in firms. We show that a tournament provides strong incentives to agents who only care about their own payoff but that it is not efficient when agents are inequity averse. In fact, inequity averse agents are attracted by a revenue-sharing scheme in which the joint production is equally distributed, under the constraint that selfish agents have no incentive to join the revenue sharing organization. If the market is perfectly flexible, this separating equilibrium induces a high effort level for both types of agents. Pareto gains are achieved by offering organizational choice to agents and the optimal contract is thus to propose both payment schemes to agents and to allow them to self-select into the different payment schemes.
\end{abstract}

JEL Classification: D63, D82, J31, J33, M52

Keywords: personnel economics, self-selection, incentives, social preferences, tournament, revenue sharing

\footnotetext{
${ }^{*}$ Professors and Ph.D. students from the Economic Department at the University of Arizona and from GATE at the University of Lyon, Joël Sobel, Pedro Rey Biel, participants at the conference on "Reciprocity: Theories and Facts" and at the 3rd International Meeting on Experimental and Behavioral Economics are acknowledged for their useful comments and suggestions. I am very grateful to Martin Dufwenberg and Marie-Claire Villeval for their important investment and advices on this work.

${ }^{\dagger}$ GATE, University of Lyon, France. E-mail: teyssier@gate.cnrs.fr.
} 


\section{Introduction}

Most organizations are divided into units or departments in which every employee does approximately the same job. In general, the joint-output of the entire unit is observable by the manager but she is unable to accurately assess individual contributions. At the same time, firms implement performance-based payment schemes to motivate individual effort within teams. O'Dell and McAdams (1987) surveyed reward practises of 1,598 U.S. organizations and found that around $75 \%$ of companies adopt a variable pay to motivate their employees. Globally, 59\% of these firms apply group incentives such as profit-sharing, gainsharing and small-group incentives, 30\% use lump-sum bonuses and 28\%, individual incentives $^{1}$. The rationale of the existence of a multiplicity of performance-based payment schemes is however still unclear. It is not obvious that a specific scheme outperforms others. An hypothesis is that a specific scheme may be more efficient with some agents but not with all agents, depending on their social preferences. People may choose different organizational structures according to their personal preferences and they may lead to better outcomes for employees and companies. The aim of this paper is to study whether the heterogeneity of workers' social preferences, such as inequity aversion, may explain the existence of multiple organizational structures through workers' self-selection. It is important to analyze whether the existence of multiple variable payment schemes increases the utility of employees and their individual production, which would raise companies' profits as well.

Lazear (2000) has shown in a study of a large auto glass American company which switched from a fixed wage to a piece-rate pay that this change enhanced the average output level per worker by 44 percent. This increase is due to both an incentive and a sorting effect in terms of abilities. Both effects are of the same extent ${ }^{2}$. Another empirical study (Hamilton, Nickerson and Owan, 2003) on people's ability heterogeneity explains that the shift from an individual piece rate payment scheme to a collective one improves workers' productivity provided that people can self-select. It has also been shown that employees working for a firm using incentive contracts with some income risk are more risk-tolerant

\footnotetext{
${ }^{1}$ Note that the sum of percentages is higher than $100 \%$ which is due to firms using several reward systems.

${ }^{2}$ Higher-ability workers are more attracted by the piece-rate pay and work at a high effort level while low-ability workers prefer the fixed wage.
} 
than the average worker (Bellemare and Shearer, 2006). These studies demonstrate that ability, education levels and risk preferences influence workers' choice of payment scheme. Individuals differ also in their social preferences and we hypothesize that this is likely to influence their occupational choice. For instance, physicians, nurses, lawyers, notaries, real estate agents or accountants decide to start their own business or to work in teams. Salesmen or, more generally, all employees whose salary includes a variable component decide to work for companies using individual or collective performance-based payment schemes. Moreover, people also choose between the public and private sectors.

Recent work indicates that people do have social preferences and that they differ in these preferences. In the standard theory, individuals are assumed to be selfish in the sense that they are pursuing only their own material payoff. However, according to Fehr and Schmidt (1999), "this may be true for some (maybe many) people, but it is certainly not true for everybody" (p. 817) ${ }^{3}$. They construct a utility function for inequity averse people which is decreasing with the spread between agents' payoffs. This means that different people like different organizations to differing degrees. In this connection, there may be Pareto gains from offering compensation/organizational choice to workers. Lazear (1989) suggests that "it may be important to sort workers in different groups depending on their personality" (p. 562). There may be no need to actually find out people's personality types, at least not directly. A flexible market that allows people to select their payment scheme may get self-selection and then an identification of personality types ex post. Our model suggests that a separating equilibrium exists and provides better outcomes to both the principal and the agents.

In our game, we consider that people are either of the selfish type or of the inequity averse type and that they are matched in groups of two agents with no information concerning the type of their co-worker. The joint-production of each group is observable by the principal but individual outputs are imperfectly measurable ${ }^{4}$. The variable payment

\footnotetext{
${ }^{3}$ Recent experimental studies show the clear existence of worker types according to their social preferences (Burlando and Guala (2005), Gächter and Thöni (2005) and Fischbacher and Gächter (2006)) and underline the necessity to consider this heterogeneity to infer adapted incentives.

${ }^{4}$ Holmstrom (1982) provides a theoretical analyzis of team incentives with moral hazard. He studies the free-riding problem and shows that it can be resolved if the owners of the firm and workers are clearly separated. He also shows that relative performance evaluation decreases costs driven by hidden
} 
attributed to workers is a positive share of the group joint production. We assume two possible payment schemes that are a tournament and a revenue-sharing scheme. Tournaments require a relative, rather than absolute, measure of individual outputs and only a proportion of group-members receive a high prize which can be, for instance, a bonus or a promotion. In two-workers groups, the payoffs distribution is degenerated in the sense that only one worker earns the whole variable pay. The revenue-sharing splits equally the global production between workers of the same group.

The first finding of our study is that the tournament is not efficient in terms of incentives for the whole population. Indeed, selfish agents who only care about their own payoff realize a high effort level under the tournament. On the contrary, inequity averse agents have to support an important disutility due to the large ex post inequality between final net payoffs. Their equilibrium effort level is then very low and may even equal zero. Therefore, working under the tournament is not profitable for inequity averse workers. By offering agents the choice of their payment scheme, to join a revenue-sharing scheme leads in equilibrium to a situation where the two types of people have sorted themselves into the two different organizations. This situation is stable: workers who do not care about the others' payoff choose the tournament organization and play the unique equilibrium which is a high effort level; inequity averse workers choose the revenue-sharing organization and exert an effort level strictly higher than the free-riding equilibrium of a game where all players are selfish, due to the application of the forward induction concept. This separating equilibrium exists under the constraint that neither selfish nor inequity averse workers wish to adopt the other organization $^{5}$. No agent can be better off in the other organizational structure and as a consequence should not move.

Moreover, we show that mono-organizational situations, i.e. situations in which all organizations are built under the same payment scheme, are unstable. On the one hand, information. Nalbatian and Schotter (1997) investigate experimentaly the effect of various group incentive payment schemes on workers' performance. They observe, among other results, that relative performancebased payment schemes have a higher incentive effect than target-based schemes on employees' production.

${ }^{5}$ In a different theoretical study on teamwork, Kosfeld and von Siemens (2006) show that people selfselect into different firms when people differ in their degree of conditional cooperation and no pooling equilibrium exists. When agents have heterogeneous productivities, Cabrales and Calvó-Armengol (2007) show that a sorting of agents by abilities is possible when their social preferences are different, even slightly, from selfish considerations. 
if we assume that all individuals work under the tournament organization, people with a sufficiently high degree of inequity aversion prefer to break away for an alternative option ${ }^{6}$. On the other hand, if all agents are assumed to work under the revenue-sharing scheme, selfish people pollute cooperation by shirking and as a consequence, everybody shirks. Then, inequity averse agents prefer to leave this organization and start another revenuesharing organization without selfish people (see Ehrhart and Keser, 1999, for experimental evidence) which is possible only if a tournament structure exists to attract selfish agents. Therefore, our model proposes a unique and separating equilibrium through the fact that workers' self-selection leads to homogeneous groups and then to adapted incentive mechanisms for each type of agents. Pareto gains are achieved from offering organizational choice to workers and the optimal contract is thus to offer both payment schemes to agents and to allow them to self-select into the different payment schemes.

The paper is organized as follow. Section 2 describes the heterogeneity of agents in terms of social preferences. Section 3 presents the tournament model with workers' equilibrium behavior. The possibility to flee the tournament is analyzed in section 4. Section 5 provides the optimal contract proposed by the principal. Section 6 discusses the results and Section 7 concludes.

\section{Heterogeneous people: selfish and inequity averse agents}

We distinguish agents according to their social preferences and, more precisely, to their degree of inequity aversion. We utilize the inequity aversion concept as defined by Fehr and Schmidt (1999). They present a utility function for inequity averse agents which is negatively affected by the difference between agents' payoffs. Bolton and Ockenfels (2000)

\footnotetext{
${ }^{6}$ Grund and Sliwka (2005) and Demougin and Fluet (2003) show that inequity aversion as defined by Fehr and Schmidt (1999) affects workers' equilibrium strategies in tournaments. Kräkel (2000) obtains the same conclusions according to the concept of "relative deprivation" introduced by Stark (1987). The study on personnel data from an English fruit farm by Bandiera, Barankay and Rasul (2005) shows that social preferences of workers have a negative impact on their productivity under relative incentives in presence of monitoring.
} 
also propose a fairness model based on distributive consequences but they develop an alternative utility function based on the comparison by each agent between their own monetary payoff and the average payoff of the reference group. Another literature studying individuals' social preferences concentrates on fairness intentions instead of final distributions. Dufwenberg and Kirchsteiger (2004) analyze intentions for sequential games in continuation of the work done by Rabin (1993) for normal games. The contribution of Falk and Fischbacher (2006) lies in the consideration of both intentions and outcome distributions to drive reciprocity. Efficiency (see Charness and Rabin, 2002) and maximin preferences characterize agents' social preferences too ${ }^{7}$. Sobel (2005) proposes a survey of this literature.

The question we address here is whether or not the presence of both selfish and inequity averse agents affects the efficiency of incentives provided by performance-based compensation schemes. We assume that the reference group of each agent is their co-worker in the team. They are neither affected by the payoff of agents belonging to another group nor by the payoff of the principal. This assumption seems to be the most adapted to our setting in which the relationship between members of the same group appears the most evident and transparent in terms of revenue information. Agents are supposed risk neutral and of the same ability level.

As in Fehr and Schmidt's, the utility function is the following for player $i$ :

$$
u_{i}\left(x_{i}, x_{j}\right)=x_{i}-\alpha_{i} \max \left\{x_{j}-x_{i}, 0\right\}-\beta_{i} \max \left\{x_{i}-x_{j}, 0\right\} \quad i \neq j
$$

where $x_{i}$ and $x_{j}$ represent the monetary payoffs of $i$ and $j$. Inequity averse individuals are assumed to be averse to both advantageous (represented by the parameter $\beta_{i}$ ) and disadvantageous inequality (represented by the parameter $\alpha_{i}$ ). Moreover, earning less than the other player has a bigger negative impact on utility than earning more, which can be written: $\alpha_{i} \geq \beta_{i}^{8}$ with $0 \leq \beta_{i}<1$. On the one hand, $\beta_{i}<1$ captures the idea that the utility of worker $i$ is always increased when his payoff rises: he is not prepared

\footnotetext{
${ }^{7}$ For an experimental comparison between these models, see Engelmann and Strobel (2004).

${ }^{8}$ If the renunciation of a fraction of the monetary payoff is lower than the gain induced by the inequality reduction, the choice of the player is rational. This is possible even for $\alpha_{i}>1$. Also, $\alpha_{i}$ does not need to be upper-bounded.
} 
to give up more (or the same amount) than his monetary payoff to reduce the inequality otherwise, being rational, his utility is reduced. On the other hand, Fehr and Schmidt exclude subjects who like earning more than others $\left(\beta_{i}<0\right)$ but, aware that this kind of preferences may exist, they show at the end of their paper that this restriction did not change the results in the games they considered. However, we can expect that the existence of this type of agents may affect the equilibrium behavior in incentive games. Also, in this paper, we allow $-1<\beta_{i}<0$ to capture the spitefulness of players ${ }^{9}$. We assume $\alpha_{i} \geq\left|\beta_{i}\right|$.

We consider an infinite population and two types of workers, $t \in\left\{t_{S}, t_{A}\right\}$. A proportion of workers $\rho, 0 \leq \rho \leq 1$, are inequity averse people with at least $\alpha \neq 0$ or $\beta \neq 0$ and $\alpha \geq|\beta|$ and $-1<\beta<1$; they are workers of type $t_{A}$. $(1-\rho)$ players, the type $t_{S}$ workers, are supposed totally selfish, i.e. $\alpha=\beta=0$. For simplicity, we suppose all type $t_{A}$ workers to have the same level of inequity aversion.

\section{The tournament}

Rank-order tournaments have a strong incentive power when agents are assumed to be selfish. We will show in this section that a tournament does not provide the same incentive effect if agents have social preferences. Inequity averse workers may be negatively affected by the high ex-post payoff inequality generated by the tournament. After a definition of the game and of the payment device under the tournament, we determine equilibrium effort levels in pure strategies and related utilities for both types of agents. We first derive the equilibrium behavior of workers under complete information in the sense that the type of agents is observable at no cost. Then, we introduce private information concerning workers' type. We study the variation of equilibrium variables in function of agents' degree of inequity aversion.

\subsection{Agents' output and payment device}

Agents, after being matched in pairs, produce a joint output that depends exclusively on their effort level. In each pair, they choose simultaneously their level of effort. The

\footnotetext{
${ }^{9}$ Frank (1985) and Mui (1995) relate the role of status seeking and envy.
} 
principal cannot observe individual contributions with certainty. Worker $i$ produces the output $e_{i}, e_{i} \geq 0$, which represents his effort level. Agents who opt for a positive effort level are submitted to a quadratic cost function, $c\left(e_{i}\right)$, such that $c\left(e_{i}\right)=e_{i}^{2}$. We assume agents identical in terms of ability then, the production technology and the effort cost function are the same for all workers ${ }^{10}$. The output produced by worker $i$ is always higher than his cost to get this output level: $e_{i} \geq e_{i}^{2} \Longleftrightarrow e_{i} \in[0,1]$. The net payoff of worker $i$ is the difference between the gross payment he received depending on effort levels exerted by both workers in the group, $p_{i}\left(e_{i}, e_{j}\right)$, and the cost associated to his effort level, $x_{i}=p_{i}\left(e_{i}, e_{j}\right)-e_{i}^{2}$. We assume here that agents are sensitive to inequality generated by final net payoffs instead of expected payoffs, which seems closer to the idea of the Fehr and Schmidt's model. Moreover, in a real company setting, as workers are able to observe the effort level of their co-worker and link their payoff and their investment in the task, it seems more realistic that they compare their final payoffs once the cost of effort is deduced.

Each group's joint production is supposed perfectly observable by the principal but she is unable to determine which amount of effort is due to each worker. As workers can lie about their effort contribution, she must use a performance-based compensation scheme in order to give employees incentives to work. We consider that workers receive a share $\tau, \tau \in[0,1]$, of the group joint-output, $Q, Q=e_{i}+e_{j}$. The tournament is not based on an absolute measure of the individual production. In fact, in each group of workers, individuals are rewarded according to the rank of their performance relative to the performance of other agents in the group. Prizes rewarded to agents are not fixed payments but are endogenous to the group output in order to avoid collusion problems. Therefore, the "winner" of the tournament earns the whole variable prize, $W\left(e_{i}, e_{j}\right)=\tau Q$, with $\tau$ chosen by the principal to maximize his profits, and the "loser" does not earn anything, $L=0$. Keeping in mind that the individual output is not perfectly observable, we consider that the winner is not the worker with the highest effort level with certainty. According to the Tullock model (1980), the probability of earning the winner's prize for each employee

\footnotetext{
${ }^{10}$ Workers' equilibrium behavior has been derived also when the production function is $f\left(e_{i}\right)$ such that $f^{\prime}\left(e_{i}\right)>0$ and $f^{\prime \prime}\left(e_{i}\right) \leq 0$ and the cost function is $c\left(e_{i}\right)$ such that $c^{\prime}\left(e_{i}\right)>0$ and $c^{\prime \prime}\left(e_{i}\right)>0$. The results are not qualitatively modified so, for simplicity, we assume $f\left(e_{i}\right)=e_{i}$ and $c\left(e_{i}\right)=e_{i}^{2}$.
} 
depends on the ratio between his own output and the group joint production:

$$
\operatorname{Pr}\left(p_{i}\left(e_{i}, e_{j}\right)=W\left(e_{i}, e_{j}\right)\right)=\operatorname{Pr}\left(p_{i}=W\right)=\frac{e_{i}}{Q}
$$

The probability of winning the prize $W\left(e_{i}, e_{j}\right)$ is increasing in the worker's effort.

\subsection{Agents' equilibrium behavior}

The von Neuman-Morgenstern utility of agent $i$ is increasing in the payoff he earns and decreasing in his cost of effort. It is given by:

$$
E\left[V_{i}\left(e_{i}, e_{j}\right)\right]=\operatorname{Pr}\left(p_{i}=W\right) \cdot v_{i}(W)+\left(1-\operatorname{Pr}\left(p_{i}=W\right)\right) \cdot v_{i}(L) \quad i \neq j
$$

The utility associated with prizes differs according to agents' social preferences. Theoretical literature on tournaments shows that this payment scheme provides important incentives to work hard when employees exclusively care about their own payoff. Nevertheless, the result may be different when workers' utility depends on the other group-member's payment. Indeed, a rank-order tournament induces a low expected utility for inequity averse agents by generating a dramatic ex post inequity when final net of cost payoffs are compared. The utility of agent $i$ of type $t_{A}$ is $^{11}$ :

$$
\begin{cases}v_{i}(W)=\tau Q-e_{i}^{2}-\beta\left[\tau Q-e_{i}^{2}+e_{j}^{2}\right] & \text { if he wins the tournament } \\ v_{i}(L)=-e_{i}^{2}-\alpha\left[\tau Q-e_{j}^{2}+e_{i}^{2}\right] & \text { if he loses the tournament }\end{cases}
$$

The expected utility of an inequity averse agent $i$ is then decreasing in $\alpha$ and $\beta$ :

$$
E\left[V_{i}\left(e_{i}, e_{j}\right)\right]=\frac{e_{i}}{Q}\left[\tau Q-\beta\left(\tau Q-\left(e_{i}^{2}-e_{j}^{2}\right)\right)\right]+\frac{e_{j}}{Q}\left[-\alpha\left(\tau Q+\left(e_{i}^{2}-e_{j}^{2}\right)\right)\right]-e_{i}^{2}
$$

If we consider an agent $k$ who is only interested in his own payoff, his utility depends exclusively on his own effort level:

$$
E\left[V_{k}\left(e_{k}\right)\right]=\tau e_{k}-e_{k}^{2} \quad \forall e_{j}
$$

As workers find their equilibrium strategy by maximizing their expected utility function, selfish people have a dominant strategy whatever the type of the other worker in the group

\footnotetext{
${ }_{e_{i}^{2}+e_{j}^{2}}^{11}$ We insure that the winner of the tournament earns always more than the loser: $\tau Q-e_{i}^{2}>e_{j}^{2} \Longleftrightarrow \tau \geq$ $\frac{e_{i}^{2}+e_{j}^{2}}{Q}$; it is verified at the equilibrium.
} 
is:

$$
e_{S}^{*}=\frac{\tau}{2}
$$

The equilibrium effort level is increasing with the share of the output given to workers.

Inequity averse agents have a different behavior according to their opponent's type ${ }^{12}$. Under complete information about the type of their co-worker in the group, the equilibrium strategy of an agent of type $t_{A}$ is:

$$
\begin{gathered}
e_{A}^{A A *}=\frac{2(1-\beta)}{2+\alpha-\beta} e_{S}^{*} \text { if his opponent is of type } t_{A} \text { as well } \\
e_{A}^{A S *}=\left\{\begin{array}{ll}
\frac{2-\alpha-3 \beta}{2(1-\beta)} e_{S}^{*} & \text { if } \alpha+3 \beta<2 \\
0 & \text { otherwise }
\end{array} \text { if his opponent is of type } t_{S}\right.
\end{gathered}
$$

Proposition 1 Under complete information, groups composed exclusively of selfish agents produce a higher output than groups containing at least one inequity averse agent: $e_{S}^{*}>$ $e_{A}^{A A *}$ and $e_{S}^{*}>e_{A}^{A S *}$. Heterogeneous groups provide the worst outcome: $e_{A}^{A A *}>e_{A}^{A S *}$. The equilibrium effort level for an inequity averse agent is decreasing in his degrees of advantageous and disadvantageous inequity aversion.

The equilibrium effort level of an agent of type $t_{A}$ is decreasing with $\alpha$ and $\beta$ whatever the type of his co-worker is. This decline is larger with reference to an increase of $\beta$ compared to an increase of $\alpha$. Consequently, in this case, the tournament does not provide good incentives to inequity averse workers if $\alpha$ and $\beta$ are high. Indeed, type $t_{A}$ workers with $\alpha+3 \beta \geq 2$ exert no effort at the equilibrium. Groups including one or two inequity averse workers produce a lower performance than groups exclusively composed of selfish workers. This difference depends on the values of $\alpha$ and $\beta$; the higher the workers' advantageous and/or disadvantageous inequity aversion, the lower the joint-production of the group. Besides, when agents types are not private information, we can infer from the reaction function of a type $t_{A}$ worker that his equilibrium effort level is decreasing with the effort level of his co-worker. An inequity averse worker exerts an even lower performance

\footnotetext{
${ }^{12}$ The reaction function of a type $t_{A}$ worker competing against a worker $j$, deduced from the maximization of his utility function, is: $e_{A}^{A j *}\left(e_{j}\right)=\frac{\tau}{2}-\frac{\alpha+\beta}{2(1-\beta)} e_{j}$.
} 
when he faces a selfish worker compared to the situation where his opponent is inequity averse too. We can see that an inequity averse worker facing another type $t_{A}$ worker always provides a positive effort level whatever $\alpha$ and $\beta$ are, whereas an inequity averse worker facing a selfish one chooses a zero effort level as soon as $\alpha+3 \beta \geq 2$.

Proposition 1 is established under the assumption that each agent's type is common knowledge. Next, we relax this assumption and assume instead that only the proportion of inequity averse people in the working population is known by agents. Type $t_{A}$ workers must maximize their expected utility knowing only the probability to compete against a selfish or another inequity averse employee. Aware that the equilibrium effort level of inequity averse agents decreases as their co-worker's effort level increases, we deduce that the equilibrium effort level of inequity averse workers under incomplete information is lower than their effort level when it is common knowledge that they face another inequity averse worker and bigger than their effort level when they face a selfish worker. Their equilibrium effort level is increasing in the proportion of inequity averse workers in the sample $\mathrm{e}^{13}$ :

$$
e_{A}^{*}= \begin{cases}\frac{2-\alpha-3 \beta+\rho(\alpha+\beta)}{2(1-\beta)+\rho(\alpha+\beta)} e_{S}^{*} & \text { if } \alpha(1-\rho)+\beta(3-\rho)<2 \\ 0 & \text { otherwise }\end{cases}
$$

Corollary 1 Under incomplete information, there exists a unique Bayesian equilibrium such that the equilibrium strategy of an inequity averse agent, increasing with $\rho$, is $e_{A}^{*} \in$ $\left[e_{A}^{A S *}, e_{A}^{A A *}\right]$ and the equilibrium strategy of a selfish agent is his dominant strategy, $e_{S}^{*}$.

The equilibrium effort level of inequity averse agents is obviously lower than the equilibrium effort level of selfish agents and is decreasing with the number of selfish agents in the population. Under both complete and incomplete informational situations, the two types of agents have a different equilibrium behavior under the tournament. Their utility is then affected as well. Contrary to selfish agents, type $t_{A}$ workers derive a very low, even negative in some cases, expected utility when their degree of inequity aversion is high, due to the degenerated allocation of incomes. We will analyze inequity averse agents' utility according to their degree of inequity aversion and the composition of their group.

\footnotetext{
${ }^{13}$ The number of workers supposed to be infinite, the type of one particular individual does not affect his beliefs about his opponant's type.
} 
Under complete information about the other group-member's type, an inequity averse agent derives a higher expected utility if his opponent is inequity averse too rather than when he is selfish. Whatever $\alpha$ and $\beta$ are and respecting the assumptions described in section 2, we obtain:

$$
E\left[V_{A}\left(e_{A}^{A A *}, e_{A}^{A A *}\right)\right] \geq E\left[V_{A}\left(e_{A}^{A S *}, e_{S}^{*}\right)\right] \forall \alpha, \beta, \alpha \geq|\beta| \text { and }-1<\beta<1
$$

At the equilibrium, the expected utility of an inequity averse worker is decreasing with $\alpha$ whatever the type of the other group-member. When $\beta$ is increasing, its negative effect on workers' utility is clear if the group is heterogeneous. The decline of the utility due to an increase of $\beta$ is slower than the one induced by an increase of $\alpha$. Further, if the group is composed of two inequity averse agents, when $\alpha$ and $\beta$ reach a sufficiently high level, the equilibrium expected utility is increasing in $\beta$. It is due to the decrease of both workers' effort level.

Under incomplete information, the equilibrium expected utility of inequity averse workers, ${ }^{I I} E\left[V_{A}\right]=\rho E\left[V_{A}\left(e_{A}^{*}, e_{A}^{*}\right)\right]+(1-\rho) E\left[V_{A}\left(e_{A}^{*}, e_{S}^{*}\right)\right]$, increases as the proportion of the population with social preferences rises. This result is obtained because their equilibrium expected utility is higher when the group is homogeneous than when they compete against a selfish employee, as in the full information situation:

$$
E\left[V_{A}\left(e_{A}^{*}, e_{A}^{*}\right)\right] \geq E\left[V_{A}\left(e_{A}^{*}, e_{S}^{*}\right)\right] \forall \alpha, \beta, \alpha \geq|\beta| \text { and }-1<\beta<1
$$

In this section, we have demonstrated that inequity averse and selfish agents do not have the same equilibrium behavior when involved in a tournament. Agents who only care about their own payment choose a high effort level at the equilibrium, whereas inequity averse agents exert a very low effort level that decreases with their degree of inequity aversion. The equilibrium utility received by inequity averse agents is weak, which suggests a probable desire to escape the tournament. Conclusions about the incentive effect of tournaments cannot be generalized to the whole working population when people are heterogeneous in terms of social preferences. 


\section{4 "Break-away" of fair-minded agents}

In the previous section, no mobility of agents was allowed. In this section, we introduce first an outside option and identify which type of agents prefers to leave the tournament. Then, we establish a second type of compensation scheme with no competition. We characterize agents who are attracted by a revenue-sharing scheme among agents who choose the outside option instead of the tournament. At the end of this section, we study whether a separating equilibrium with selfish people compensated according to the tournament and inequity averse people according to the revenue-sharing scheme exists.

\subsection{An outside option}

We consider an outside option, strategy $X$, which consists of staying out of the organization, which means avoiding the tournament game. In the context of principal-agent theory, the outside option gives individuals their reservation utility, $\underline{u} \geq 0$, which is identical for all agents. As people who leave the tournament for the outside option are not directly connected to other people, they do not compare their payoff to others'. $\underline{u}$ is then independent of others' payoff even for fair-minded workers.

A selfish agent $k$ prefers to work under the tournament than to take the outside option if:

$$
E\left[V_{k}\left(e_{S}^{*}\right)\right]=\tau e_{S}^{*}-e_{S}^{* 2} \geq \underline{\mathrm{u}} \Longleftrightarrow \tau \geq 2 \sqrt{\underline{\mathrm{u}}}
$$

As the expected utility derived at the equilibrium by an inequity averse agent from being compensated according to a tournament is decreasing in $\alpha$ and $\beta$, his participation constraint is harder to be satisfied when his inequity aversion degrees are high. The participation constraint is the following:

$$
{ }^{I I} E\left[V_{A}\right]=\rho E\left[V_{A}\left(e_{A}^{*}, e_{A}^{*}\right)\right]+(1-\rho) E\left[V_{A}\left(e_{A}^{*}, e_{S}^{*}\right)\right] \geq \underline{\mathrm{u}}
$$

We characterize $\beta^{*}(\alpha)$ such that $\rho E\left[V_{A}\left(e_{A}^{*}, e_{A}^{*}\right)\right]+(1-\rho) E\left[V_{A}\left(e_{A}^{*}, e_{S}^{*}\right)\right]=\underline{\mathrm{u}}$. Then, agents with $\beta \geq \beta^{*}(\alpha)$ do not satisfy the tournament participation constraint and prefer to receive their reservation utility than to work under the tournament. It is equivalent to saying that when $\alpha$ and $\beta$ are big enough, workers prefer to avoid the tournament because, caring too 
much about others' payoffs, their utility from earning a wage very different from that of their opponent is lower than the one they can get from staying out of the organization. The more the disadvantageous inequity aversion of the agent is high, the more the threshold of advantageous inequity aversion necessary for the outside option to be preferable to the tournament is low.

If inequity averse agents leave the tournament for an outside option, we must be sure that once they have all left, i.e. once all the selfish workers are employed under the tournament and all the inequity averse workers have chosen the outside option, they have no interest in deviating which signifies, to join the tournament when all the contestants are selfish. We have $E\left[V_{A}\left(e_{A}^{A S *}, e_{S}^{*}\right)\right]=E\left[V_{A}\left(e_{A}^{*}, e_{S}^{*}\right)\right]$ for $\rho=0$. It implies that if inequality (9) is unproven, $E\left[V_{A}\left(e_{A}^{A S *}, e_{S}^{*}\right)\right]<\underline{\mathrm{u}}$ is inevitably verified. Once all type $t_{A}$ agents with $\beta \geq \beta^{*}(\alpha)$ have quit the tournament for their reservation utility, none of them have an interest to deviate by going back into the tournament. We find a unique equilibrium described by the following proposition.

Proposition 2 Under incomplete information, if type $t_{A}$ agents are characterized by $\beta \geq \beta^{*}(\alpha)$, there exists a unique and separating perfect Bayesian equilibrium with strategy profiles such that $\left(e_{S}^{*} \mid t_{S}\right)$ and $\left(X \mid t_{A}\right)$ whatever the beliefs on agents' type.

Once the sorting done, none of the agents, whatever their type is, have an interest in deviating from this situation. Moreover, no pooling situation is stable. When both types of workers are employed under the tournament, inequity averse ones prefer to take the outside option and selfish workers stay in the tournament. When all of them receive their outside option, only selfish workers prefer to work under the tournament. For the remainder of the paper, we consider that advantageous inequity aversion of type $t_{A}$ workers is such that $\beta \geq \beta^{*}(\alpha)$. Indeed, the case we focus on corresponds to the situation in which inequity averse workers prefer to avoid the tournament. Nevertheless, we will discuss different cases corresponding to various inequity aversion levels in section 5 . 


\subsection{Another organizational structure: revenue-sharing}

In the labor market, agents can choose the organization they prefer to work for. Indeed, inequity averse agents may be more interested in working under a compensation scheme which does not create such a strong inequality between workers' payoffs. We consider here another payment scheme more adapted to inequity averse workers in terms of expected utility derived. Revenue-sharing reduces the spread between workers' gross payoffs to zero by dividing equally the joint production between group members. This payment scheme is related to public goods games in the sense that the whole group contribution is equally shared between agents regardless of their personal investment. Consequently, agents who do not care about the other group-member's payoff free-ride ${ }^{14}$. However, the revenuesharing scheme may attract inequity averse agents with a high effort level investment provided that there are no free-riders in the group. We note $v, v \in[0,1]$, the share of the joint-output distributed by the principal to agents.

Inequity averse agents' utility function is then written:

$$
U_{i}\left(e_{i}, e_{j}\right)=\left\{\begin{array}{cc}
\frac{1}{2} v\left(e_{i}+e_{j}\right)-e_{i}^{2}-\alpha\left(e_{i}^{2}-e_{j}^{2}\right) & \text { if } e_{i}>e_{j} \\
\frac{1}{2} v\left(e_{i}+e_{j}\right)-e_{i}^{2}-\beta\left(e_{j}^{2}-e_{i}^{2}\right) & \text { if } e_{i}<e_{j} \\
\frac{1}{2} v\left(e_{i}+e_{j}\right)-e_{i}^{2} & \text { if } e_{i}=e_{j}
\end{array}\right.
$$

As we assume that agents compare their net payoffs, even with an egalitarian distribution of the output produced, the utility of agents is reduced if both group-members do not realize the same effort level. Selfish workers play their dominant strategy at the equilibrium, $\hat{e}_{S}=\frac{v}{4}$, which is what we call in the following the "free-riding equilibrium" whereas the Pareto optimum is $\hat{e}^{O P}=\frac{v}{2}$. The equilibrium effort level in pure strategies of inequity averse workers is $\hat{e}_{A}=\hat{e}_{S}$ as well if $\rho \leq \frac{\beta}{\alpha+\beta}$. At the same time, multiple equilibria exist for inequity averse agents if the proportion of fair-minded people in the working population is

\footnotetext{
${ }^{14}$ When all players of the game are supposed to have no social considerations, to free-ride is the unique equilibrium. The experimental evidence shows however that many people contribute more than the theory predicts (see Ledyard (1995) for a survey) which supports a heterogeneity of types.
} 
high enough. Inequity averse agents' equilibrium effort level is $\hat{e}_{A}$ such that:

$$
\hat{e}_{A} \in\left\{\begin{array}{cl}
\hat{e}_{S} & \text { if } \rho \leq \frac{\beta}{\alpha+\beta} \\
{\left[\frac{1}{1+\alpha \rho-\beta(1-\rho)} \hat{e}_{S}, \hat{e}_{S}\right]} & \text { if } \frac{\beta}{\alpha+\beta}<\rho \leq \frac{\alpha}{\alpha+\beta} \\
{\left[\frac{1}{1+\alpha \rho-\beta(1-\rho)} \hat{e}_{S}, \frac{1}{1+\alpha(1-\rho)-\beta \rho} \hat{e}_{S}\right]} & \text { if } \rho>\frac{\alpha}{\alpha+\beta}
\end{array}\right.
$$

We consider that the equilibrium effort level of inequity averse agents is never higher than the Pareto optimum because whatever the strategy of $j$, the expected utility of agent $i$ is decreasing as his effort level increases beyond the optimal effort level (even without taking into account the reduction in utility due to inequity). The unique Bayesian equilibrium is the free-riding equilibrium when the proportion of inequity averse agents is not sufficiently high. This proportion must be at least one half to possibly observe the equilibrium effort level of inequity averse agents higher than $\hat{e}_{S}$. If both agents of each group are inequity averse and this is common knowledge, multiple symmetric equilibria always exist.

Proposition 3 If it is common knowledge that all agents compensated under the revenuesharing payment scheme are type $t_{A}$ agents, there exist multiple symmetric equilibria $\hat{e}_{A}$ such that: $\frac{v}{4(1+\alpha)} \leq \hat{e}_{A} \leq \frac{v}{4(1-\beta)}$.

\section{PROOF: see Appendix.}

When it is common knowledge that all participants in the revenue-sharing organization are fair-minded, the free-riding equilibrium is not unique. As type $t_{A}$ agents are supposed to be identical, all the equilibria of the revenue-sharing game are symmetric. Their interval increases with inequity aversion degrees: the lower bound of the equilibria set is increasing with $\alpha$ and the upper bound with $\beta$. Consequently, the Pareto optimum of the revenue-sharing game, $\hat{e}^{O P}$, becomes an equilibrium if it is common knowledge that all the participants have a degree of advantageous inequity aversion high enough, $\beta \geq \frac{1}{2}$. Fairminded agents with $\beta>0$ who avoid the tournament for the revenue-sharing scheme are able to reach an equilibrium inducing a higher effort level than the free-riding equilibrium under the constraint that selfish workers do not join the revenue-sharing organization. Nevertheless, the free-riding situation is still an equilibrium even if everybody is fair-minded and aware of it. As we cannot assume that players coordinate their expectations on a 
particular equilibrium and as the Nash equilibrium concept does not resolve the problem of multiple equilibria selection when strategies are weakly dominated, we need to apply one of its refinements to restrict the set of equilibria. The concept of forward induction permits this equilibria selection ${ }^{15}$.

To verify the existence of a separating equilibrium, we assume first that all agents working under the revenue-sharing scheme are inequity averse. We study the conditions for advantageous inequity aversion to allow for a symmetric equilibrium with effort levels strictly higher than $\hat{e}_{S}$. Once this is determined, we will check the stability of the situation and if a pooling equilibrium can exist.

An inequity averse agent $i$ prefers to work under the revenue-sharing scheme than to take the outside option if $U_{i}\left(\hat{e}_{A}, \hat{e}_{A}\right) \geq \underline{\mathrm{u}}$ with $\hat{e}_{A} \in\left[\frac{v}{4(1+\alpha)}, \frac{v}{4(1-\beta)}\right]$. Then, the forward induction concept specifies that an agent choosing the revenue-sharing scheme sends a signal to other agents that he enters the game with the objective of earning more than $\underline{u}$, i.e. he wants to reach an equilibrium, $\hat{e}_{A}$, from the set of possible equilibria defined by (10) such that $U_{i}\left(\hat{e}_{A}, \hat{e}_{A}\right) \geq \underline{\mathrm{u}} \Longleftrightarrow v \hat{e}_{A}-\hat{e}_{A}^{2} \geq \underline{\mathrm{u}}$. If we assume $\underline{\mathrm{e}}_{A}$ being the effort level which keeps the worker indifferent between the outside option and the revenue-sharing scheme, i.e. $v \underline{\mathrm{e}}_{A}-\underline{\mathrm{e}}_{A}^{2}=\underline{\mathrm{u}} \Longleftrightarrow \underline{\mathrm{e}}_{A}=\frac{v-\sqrt{v^{2}-4 \underline{\mathrm{u}}}}{2}$, and $\bar{e}_{A}$, the maximum equilibrium effort level reachable, increasing with $\beta, \bar{e}_{A}=\left\{\begin{array}{cl}\frac{v}{2} & \text { if } \beta \in\left[\frac{1}{2}, 1\right) \\ \frac{v}{4(1-\beta)} & \text { if } \beta \in\left[\hat{\beta}, \frac{1}{2}\right)\end{array}\right.$, the set of equilibria is then restricted to $\hat{e}_{A}$ such that $\hat{e}_{A} \in\left[\underline{\mathrm{e}}_{A}, \bar{e}_{A}\right]$. In order to have $\underline{\mathrm{e}}_{A}$ higher than the free-riding equilibrium and lower than the optimum, we impose:

$$
v \in\left[2 \sqrt{\underline{\mathrm{u}}}, \frac{4 \sqrt{3}}{3} \sqrt{\underline{\mathrm{u}}}\right]
$$

An agent with $\beta \geq \hat{\beta}$ prefers to enter the revenue-sharing organization than to take the

\footnotetext{
${ }^{15}$ The main theoretical works about the concept of forward induction includes Kohlberg and Mertens (1986), van Damme (1989) and Battigalli and Siniscalchi (2002). Asheim and Dufwenberg (2003) treat a very similar intuition to ours although they do not base workers' characteristics on the Fehr and Schmidt's model. They show that forward induction makes the selection of the Pareto-dominant equilibrium possible in a coordination game with discrete strategies (they use another group incentive game: "forcing contracts"). According to the definition advanced by Cooper et al. (1992), a coordination game consists of multiple, Pareto-rankable and pure strategy Nash equilibria. Henceforth, the revenue-sharing game with players having a sufficiently high advantageous inequity aversion is included in this category of games.
} 
outside option. The advantageous inequity aversion threshold is then:

$$
\hat{\beta}=1-\frac{v}{4 \underline{\mathrm{e}}_{A}}
$$

For the remaining of the paper, we assume that inequity averse agents have an advantageous inequity aversion degree verifying $\beta \geq \hat{\beta}$ in addition to $\beta \geq \beta^{*}(\alpha)$.

This restriction on advantageous inequity aversion allows us to observe equilibrium effort levels with revenue-sharing higher than $\hat{e}_{S}$. Nevertheless, an equilibrium with effort levels higher than the free-riding strategy does exist if and only if no selfish worker has an incentive to enter this organizational structure. Each group is composed once agents have entered the revenue-sharing game, which means that an agent having chosen to leave the tournament and not to take the outside option infers that he plays with someone who made the same choice as him. Consequently, both workers send a signal about their intentions to play an effort level equal to or higher than $\underline{\mathrm{e}}_{A}$. The necessary and sufficient condition to observe this high effort levels equilibrium is that selfish agents prefer to work under the tournament than to join the revenue-sharing organization and take advantage of fair-minded workers by playing their dominant strategy, $\hat{e}_{S}$, which is to free-ride. Due to the difficulty for people to coordinate on the same equilibrium strategy under the revenuesharing scheme with certainty, this condition must be verified $\forall \hat{e}_{A} \in\left[\underline{\mathrm{e}}_{A}, \bar{e}_{A}\right]$. It is written:

$$
E\left[V_{S}\left(e_{S}^{*}\right)\right] \geq \max _{\hat{e}_{A} \in\left[\underline{e}_{A}, \bar{e}_{A}\right]} U_{S}\left(\hat{e}_{A}, \hat{e}_{S}\right) \Longleftrightarrow E\left[V_{S}\left(e_{S}^{*}\right)\right] \geq U_{S}\left(\bar{e}_{A}, \hat{e}_{S}\right)
$$

$\bar{e}_{A}$ is the maximum equilibrium effort level for inequity averse agents and it provides the maximum expected utility for selfish agents who free-ride.

It is equivalent to: $\tau e_{S}^{*}-\frac{v}{2}\left(\bar{e}_{A}+\hat{e}_{S}\right) \geq e_{S}^{* 2}-\hat{e}_{S}^{2}$

$$
\Longleftrightarrow\left\{\begin{array}{cc}
4 \tau^{2}-5 v^{2} \geq 0 & \text { if } \beta \in\left[\frac{1}{2}, 1\right) \\
4 \tau^{2}(1-\beta)-v^{2}(3-\beta) \geq 0 & \text { if } \beta \in\left[\hat{\beta}, \frac{1}{2}\right)
\end{array}\right.
$$

Condition (13) is verified if the share of the joint-output given to the agent who won the tournament, $\tau$, is high enough and the share of the joint-output given to the agents in the revenue-sharing scheme, $v$, is low enough. The larger $\beta$, the higher the upper bound of 
the equilibria set and then, the higher the utility derived by a selfish worker who shirks. Hence, inequality (13) is harder to verify than when $\beta$ is low.

Inequity averse agents prefer to work in the revenue-sharing organization once the two types of agents are sorted into the different payment schemes:

$$
\begin{aligned}
E\left[V_{A}\left(e_{A}^{A S *}, e_{S}^{*}\right)\right] \leq & \min _{\hat{e}_{A}} U_{A}\left(\hat{e}_{A}, \hat{e}_{A}\right) \forall \hat{e}_{A} \text { such that } U_{A}\left(\hat{e}_{A}, \hat{e}_{A}\right) \geq \underline{\mathrm{u}} \\
& \Longleftrightarrow E\left[V_{A}\left(e_{A}^{A S *}, e_{S}^{*}\right)\right] \leq \underline{\mathrm{u}}
\end{aligned}
$$

We showed in subsection 4.1 that this inequality is always verified if the advantageous inequity aversion of type $t_{A}$ workers is such that $\beta \geq \beta^{*}(\alpha)$, which means that inequity averse workers never gain from leaving the revenue-sharing scheme for the tournament.

Therefore, a separating equilibrium exists in which all people are as well off or better off than when everybody plays the tournament. Inequity averse agents who choose the outside option in preference to the tournament when there is no available alternative prefer to move to the revenue-sharing organization. It leads to proposition 4 showing that once agents are sorted such that selfish agents choose the tournament and inequity averse agents choose the revenue-sharing scheme, nobody has an incentive to deviate. Moreover, this separating equilibrium is unique and no pooling situation is stable.

Proposition 4 A unique and separating perfect Bayesian equilibrium with strategy profiles such that $\left(e_{S}^{*} \mid t_{S}\right)$ and $\left(\hat{e}_{A} \mid t_{A}\right)$ and beliefs such that $b_{i}\left(t_{S} \mid e_{S}^{*}\right)=b_{i}\left(t_{A} \mid \hat{e}_{A}\right)=1$ exists if $\tau$ and $v$ are such that inequality (13) is satisfied.

PROOF: see Appendix.

Fair-minded agents receive a very low expected utility when they work in an organization applying a competitive compensation scheme yielding to a dramatic ex post inequality between group-members' payoffs. For sufficiently high inequity aversion degrees, these workers are even willing to quit the tournament to receive only their reservation utility in order to avoid this important inequality. If we consider another organization which distributes equally the joint-output between group-members, we observe that agents with sufficiently high degrees of inequity aversion leave the tournament for the revenue-sharing 
organization under the condition that selfish workers have an incentive to stay in the tournament and inequity averse agents have an incentive to participate in the revenue-sharing scheme instead of staying out of the production process. Hence, all agents realize a positive and high effort level in their job. $(1-\rho)$ is the share of workers compensated according to the tournament and $\rho$ the share choosing the revenue-sharing scheme. The object now is to analyze the optimal contract for the principal. On the one hand, she must decide the percentage of groups' joint output to include in workers' wages. On the other hand, she must choose which payment scheme, between the tournament and the revenue-sharing scheme, to implement or both of them with agents allowed to self-select.

\section{The optimal contract}

We showed in the previous section that inequity averse agents prefer to run away from the tournament for an egalitarian partnership payment scheme while selfish agents have a higher expected utility under tournaments. The incentive effect of both performancebased payment schemes are then improved when agents are allowed to self-select into the organization using the compensation mode most adapted to their preferences. The sorting of workers into the two compensation schemes implies homogeneous groups in the sense that workers in a particular group have the same type of social preferences, in terms of inequity aversion. Knowing that they are working with someone having the same orientation, the incentive effect of each payment scheme is improved. None of the agents decide to stay out of both games, which means that every agent adds his contribution to the global output by working, which is not the case in the presence of the tournament alone. Not considering the possible self-selection of agents who differ in their degree of inequity aversion may lead to a very important misunderstanding of organizations' incentives design. We show here that offering workers the choice between the two different variable compensation schemes is beneficial to both employees and employers.

In this game, we consider that the market is perfectly flexible. Both types of agents can choose their organizational structure, i.e. their compensation system, without any restriction. Consequently, this game consists of three stages: 
- $1^{\text {st }}$ stage: a principal chooses to offer only a tournament payment scheme or a revenue-sharing scheme, or both the tournament and the revenue-sharing compensation schemes, with optimal $\tau$ and $v$;

- $2^{\text {nd }}$ stage: agents choose simultaneously to enter the tournament $(T)$, the revenuesharing organization $(R)$ or to take the outside option $(X)$;

- $3^{\text {rd }}$ stage: agents who chose to participate in one of the two games at the $1^{\text {st }}$ stage are matched with another agent having done the same choice and then, they simultaneously decide their effort level without any information about the type of their co-worker.

We have resolved $2^{\text {nd }}$ and $3^{\text {rd }}$ stages in the previous sections. We know the equilibrium effort levels of agents when only the tournament or the revenue-sharing scheme or the tournament and the revenue-sharing scheme are proposed to the workers. The first step is now to define the optimal contract for the principal in each situation. Her action variables are the share of the global output given to workers under the tournament, $\tau$, and the revenue-sharing scheme, $v$.

The maximization program of the principal when she proposes only the tournament is written:

$$
\begin{aligned}
& \max _{\tau_{\text {tour }}} \Pi_{\text {tour }}=(1-\rho)(1-\tau) e_{S}^{*} \\
& \text { s.t. } \tau \in[2 \sqrt{\underline{\underline{u}}}, 1]
\end{aligned}
$$

The optimal share ${ }^{16}$ is $\tau_{\text {tour }}^{*}=\frac{1}{2}$.

When she proposes only the revenue-sharing scheme, her maximization program is:

$$
\begin{gathered}
\max _{\tau_{\text {rev }}}\left\{\begin{array}{cc}
\Pi_{\text {rev }}=(1-v) \hat{e}_{S} & \text { if } \rho \leq \frac{\beta}{\alpha+\beta} \\
\Pi_{r e v}=(1-v)\left(\rho \hat{e}_{A}+(1-\rho) \hat{e}_{S}\right) & \text { if } \rho>\frac{\beta}{\alpha+\beta}
\end{array}\right. \\
\text { s.t. } v \in\left[2 \sqrt{\underline{\mathbf{u}}}, \frac{4 \sqrt{3}}{3} \sqrt{\underline{\mathrm{u}}}\right](11)
\end{gathered}
$$

\footnotetext{
${ }^{16}$ We assume $\underline{u} \leq \frac{1}{16}$ in order to be more realistic and to obtain an optimal contract independant of people reservation utility; if $\underline{\mathrm{u}}>\frac{1}{16}, \tau_{\text {tour }}^{*}=2 \sqrt{\underline{\mathrm{u}}}$.
} 
The optimal share is then $v_{r e v}^{*}=\frac{1}{2}$.

The offer of the tournament or the revenue-sharing when we consider mono-organizational structures depends on the percentage of inequity averse agents in the whole working population. The higher $\rho$, the higher the principal's profit under the revenue-sharing scheme and the lower under the tournament. Consequently, the principal's interest in using the tournament mechanism design is decreasing with $\rho^{17}$.

The principal's maximization program is subject to an additional cost when she proposes both the tournament and the revenue-sharing scheme and allows the agents to selfselect. In fact, the positive effect derived from the offer of both payment schemes lies in the existence of the unique separating equilibrium. This is possible if and only if constraint (13) is verified. The program is the following ${ }^{18}$ :

$$
\begin{aligned}
& \underset{\tau_{\text {selec }}, v_{\text {selec }}}{\max } \Pi_{\text {selec }}=(1-\rho)(1-\tau) e_{S}^{*}+\rho(1-v) \hat{e}_{A} \text { with } \hat{e}_{A} \in\left[\underline{\mathrm{e}}_{A}, \bar{e}_{A}\right] \\
& \text { s.t.(8) (11) (13) }
\end{aligned}
$$

We note $\hat{e}_{A}=\frac{v}{4(1-\gamma)}$. The optimal share given to agents in the tournament, $\tau_{\text {selec }}^{*}$, is an increasing linear function of the share given to the agents in the revenue-sharing scheme: $\tau_{\text {selec }}^{*}=\frac{\sqrt{5}}{2} v_{\text {selec }}^{*}$ if $\beta \in\left[\frac{1}{2}, 1\right)$ and $\tau_{\text {selec }}^{*}=\frac{\sqrt{(3-\beta)(1-\beta)}}{2(1-\beta)} v_{\text {selec }}^{*}$ if $\beta \in\left[\hat{\beta}, \frac{1}{2}\right)$.

$$
v_{\text {selec }}^{*}=\left\{\begin{array}{cl}
\frac{\sqrt{5}(1-\gamma)(1-\rho)+\rho}{5-3 \rho-5 \gamma(1-\rho)} & \text { with } \gamma \in\left[\hat{\beta}, \frac{1}{2}\right] \text { if } \beta \in\left[\frac{1}{2}, 1\right) \\
\frac{A(1-\gamma)(1-\rho)+(1-\beta) \rho}{3-\rho-3 \gamma(1-\rho)-\beta(1+\rho-\gamma(1-\rho))} & \text { with } \gamma \in[\hat{\beta}, \beta] \quad \text { if } \beta \in\left[\hat{\beta}, \frac{1}{2}\right), A=\sqrt{3-4 \beta+\beta^{2}}
\end{array}\right.
$$

The principal increases the share given to the workers in the revenue-sharing scheme as the proportion of fair-minded agents in the whole population rises. Moreover, this share increases with $\gamma$, which indicates the level of the effective equilibrium effort level. Nevertheless, nobody is able to evaluate correctly $\hat{e}_{A}$, which means that the principal must establish the contract based on his expectations concerning the equilibrium effort level played in various groups. Therefore, the less accurate his estimation of $\hat{e}_{A}$, the greater the

\footnotetext{
${ }^{17} \Pi_{\text {tour }}^{*} \geq \Pi_{\text {rev }}^{*}$ if $0 \leq \rho \leq \frac{1}{2}$ when $\rho \leq \frac{\alpha}{1+\alpha}$ (case 1) and if $0 \leq \rho \leq \frac{-(1+\alpha) \sqrt{2(1+\alpha)}}{1-\alpha}$ when $\rho>\frac{\alpha}{1+\alpha}$ (case 2 ). We can note that if $0 \leq \alpha<1$, the tournament is always prefered to the revenue-sharing in case 1 , but, in case 2 , the tournament may be chosen only if $0 \leq \alpha<1$.

${ }^{18}$ As we cannot select a unique equilibrium under the revenue-sharing scheme, we must consider the whole set of equilibria as a possible situation.
} 
distance between his profit and the optimal profit.

At the optimum, we obtain:

$$
\left\{\begin{array}{c}
\Pi_{\text {selec }}^{*}\left(\tau_{\text {selec }}^{*}, v_{\text {selec }}^{*}\right) \geq \Pi_{\text {tour }}^{*}\left(\tau_{\text {tour }}^{*}\right) \\
\Pi_{\text {selec }}^{*}\left(\tau_{\text {selec }}^{*}, v_{\text {selec }}^{*}\right) \geq \Pi_{\text {rev }}^{*}\left(v_{\text {rev }}^{*}\right)
\end{array} \forall \hat{e}_{A} \in\left[\underline{\mathrm{e}}_{A}, \bar{e}_{A}\right] \text { and } \forall \beta \in[\hat{\beta}, 1)\right.
$$

Proposition 5 If the principal knows $\rho$ with certainty and that the inequity averse agents have an advantageous inequity aversion greater than $\beta^{*}(\alpha)$ and $\hat{\beta}$, she always prefers to offer both payment schemes and to allow agents to self-select into these different payment schemes.

The principal always profits by proposing both the tournament and the revenue sharing payment schemes and to allow agents to choose one of them according to their individual preferences instead of one payment device alone. The profit deduced is strictly increasing with the effort level equilibrium under the revenue-sharing scheme. Although a positive proportion of inequity averse agents induces superior profits when the principal proposes both payment schemes, these profits are increasing with the proportion of inequity averse agents only if the equilibrium effort level under the revenue sharing scheme equals or almost equals the Pareto optimum under the condition that $\rho$ is high enough ${ }^{19}$. It is clearly decreasing for $\hat{e}_{A}$ such that $\gamma \in[\hat{\beta}, 0.493]$. This may be explained by the fact that the optimal share given to workers is increasing with $\rho$, which is then more costly for the principal.

The share given to agents under the tournament depends positively on $\rho$. Therefore, when the population is exclusively composed of selfish people, the principal adapts $v_{\text {selec }}^{*}$ and $\tau_{\text {selec }}^{*}$ to the context and $\tau_{\text {selec }}^{*}=\tau_{\text {tour }}^{*}$. When constraint (13) is verified, selfish agents choose the tournament with certainty and then, we obtain $\Pi_{\text {selec }}^{*}\left(\tau_{\text {selec }}^{*}, v_{\text {selec }}^{*}\right)=$ $\Pi_{\text {tour }}^{*}\left(\tau_{\text {tour }}^{*}\right)$. Therefore, as soon as the principal knows with certainty the proportion of the working population who have social preferences, she has a strict advantage in propos-

\footnotetext{
${ }^{19}$ To be more precise the necessary condition to observe $\frac{\partial \Pi_{\text {selec }}^{*}}{\partial \rho}>0$ is to have $\hat{e}_{A}$ such that $0.493<\gamma \leq \frac{1}{2}$ if $\beta \geq \frac{1}{2}$. If $\beta \in\left[\hat{\beta}, \frac{1}{2}\right)$, the interval on $\gamma$ and $\beta$ is even more reducted and cases are such rare that we consider only cases related to $\beta \geq \frac{1}{2}$. Few examples: for $\gamma=0.493, \rho>0.996$ is needed to obtain $\frac{\partial \Pi_{\text {selec }}^{*}}{\partial \rho}>0$; for $\gamma=0.497, \rho>0.75$ is needed; for $\gamma=0.5, \rho>0.528$ is needed.
} 
ing both compensation modes. Nevertheless, she may not know $\rho$ perfectly and in this case, she must make an estimation $\hat{\rho}=\rho+\Delta$ with $\Delta \in[-\rho, 1-\rho]$. To over-estimate $\rho$ is the most costly to the principal because it induces higher $\tau_{\text {selec }}^{*}$ and $v_{\text {selec }}^{*}$ than necessary. However, allowing agents to self-select into the organizational structure they prefer almost always leads to higher profits than proposing only one payment scheme. It is profitable for the principal to offer the tournament alone only for values of $\rho$ very closed to $0(\rho<0.028)$. Even if the principal makes some estimation errors about the proportion of inequity averse people in the working population, it is unlikely that he would lose profits by offering both payment schemes.

To offer an organizational choice to agents is then in everyone's interest. On the one hand, all workers realize a high effort level due to the realization of homogeneous groups driven by workers' choices. Selfish people work under the tournament and inequity averse people under the revenue-sharing. On the other hand, the principal gains from proposing both payment schemes to agents and allowing for self-selection, through the global improvement of workers' productivity. Pareto gains are then achieved.

In our game, we consider a single firm, represented by a principal, who decides to offer one payment scheme, the tournament or the revenue-sharing scheme, or both compensation schemes. Her optimal behavior is overwhelmingly the last option. Another formalization would have been to suppose that several firms are allowed to propose simultaneously one type of variable payment scheme each. In this case, the self-selection of agents would be realized between firms. Our result is robust to this change under the assumption that people move to another firm only if it assures them a strictly higher utility. We observe that there exists a unique equilibrium which separates the two types of agents into the two different payment schemes when firms are subject to competition to attract workers if inequality (13) is verified ${ }^{20}$.

\footnotetext{
${ }^{20}$ Suppose that there is one firm on the market using only one payment scheme. A new firm has an interest in entering the market and offering the payment scheme so far absent to attract one type of workers. Both firms realize a positive profit in this case. Then, other firms wish to enter this market as well. Companies who offer the tournament receive zero profits $\left(\tau^{*}=1\right)$ at the equilibrium because of competition. Companies who offer the revenue-sharing collect positive profits because of the upper bound of $v^{*}$ due to the verification of inequality (13). This situation is stable because firms who offer the tournament have no interest in deviating by proposing the revenue-sharing scheme. Indeed, they would get no worker by choosing $v=v^{*}$ and would cancel the separating equilibrium by choosing $v>v^{*}$. In this
} 


\section{Discussion}

Some assumptions of our study require a discussion. First, we discuss the optimal behavior of the principal for all possible degrees of inequity aversion of inequity averse agents. Indeed, in our study, we assumed $\beta \geq \beta^{*}(\alpha)$ and $\beta \geq \hat{\beta}$. Secondly, we analyze whether our results are robust when the principal derives an additional benefit from cooperation under the revenue-sharing scheme. Then, we propose qualitative results when endogenous payment schemes are considered and finally, we suggest intuitions for long term interactions.

We have assumed throughout the paper that inequity aversion of agents is such that they prefer to leave the tournament for an outside option, $\beta \geq \beta^{*}(\alpha)$, but prefer to participate in another game, revenue sharing, instead of the outside option, $\beta \geq \hat{\beta}$. Nevertheless, other cases exist. They are represented in the following graph.

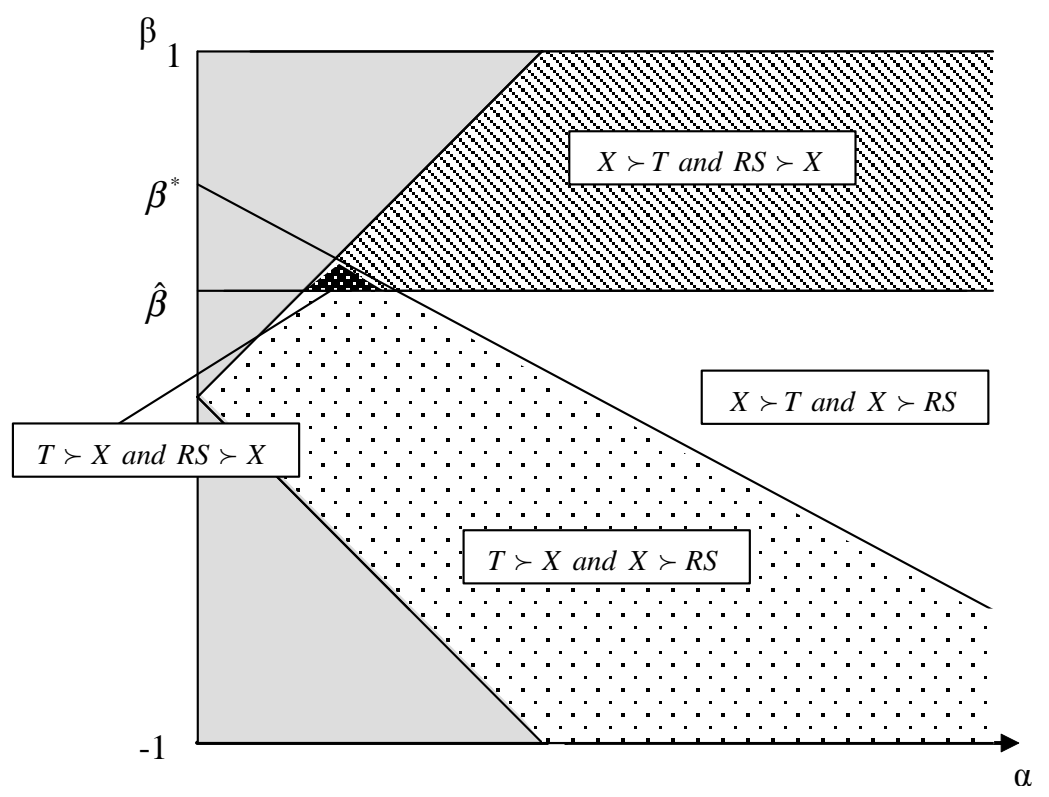

Fig. 1. Different categories of workers as a function of $\alpha$ and $\beta$

According to the graph, we can differentiate four cases. We first assume that the range of degrees of inequity aversion of inequity averse agents is common knowledge for all agents and the principal. In case 1, represented by lines on the graph, the principal proposes both case, selfish workers would be attracted by the revenue-sharing organization and destroy any cooperation. Moreover, profits realized by firms offering the revenue-sharing scheme is decreasing with the number of firms. For a large number of these firms, their profits would tend to zero. 
payment schemes (case analyzed previously) and his optimal profit is $\Pi_{\text {selec }}^{*}$. In case 2 , in white, no inequity averse agent chooses to enter either game $\left(\beta \geq \beta^{*}(\alpha)\right.$ and $\left.\beta<\hat{\beta}\right)$ then, the principal chooses to implement only the tournament and his profit is $\Pi_{\text {tour }}^{*}$ with a unique equilibrium effort level, $e_{S}^{*}$. In cases 3 and 4 , symbolized by dots, the principal proposes only the tournament and his profit is $\Pi_{\text {tour }}^{*}$ with $e_{S}^{*}$ and $e_{A}^{*}$ at the equilibrium ${ }^{21}$, noted ${ }^{\left(\beta<\beta^{*}(\alpha)\right)} \Pi_{\text {tour }}^{*}$. If we suppose that the principal cannot observe the level of the social preferences of agents, she has to take into account probabilities on ranges of $\alpha$ and $\beta$ to decide to implement only the tournament or to give workers the choice between the tournament and the revenue-sharing scheme. In fact, it is more costly for the principal to offer both payment schemes than only the tournament because she has to implement a higher $\tau$ in order to verify inequality (13) which is the condition for the existence of a unique separating equilibrium. We note by $p_{1}$ the probability of observing inequity aversion degrees such that $\beta \geq \beta^{*}(\alpha)$ and $\beta \geq \hat{\beta}$, by $p_{2}$ the probability that $\beta \geq \beta^{*}(\alpha)$ and $\beta<\hat{\beta}$ and by $p_{3}$ the probability that $\beta<\beta^{*}(\alpha)$. She proposes a choice between payment schemes, under the constraint that $p_{1}+p_{2}+p_{3}=1$, if ${ }^{22}$ :

$$
p_{1} \Pi_{\text {selec }}^{*}\left(\tau_{\text {selec }}^{*}, v_{\text {selec }}^{*}\right) \geq p_{2} \Pi_{\text {tour }}^{*}\left(\tau_{\text {tour }}^{*}\right)+p_{3}{ }^{\left(\beta<\beta^{*}(\alpha)\right)} \Pi_{\text {Tour }}^{*}\left(\tau_{\text {tour }}^{*}\right)
$$

Replacing $p_{2}$ by $1-p_{1}-p_{3}$, we find that inequality (15) is verified if $p_{3}$ is not too big and $p_{1}$ is high enough. The inequality is harder to satisfy with increasing $p_{3}$. As a general result, the probability that $\alpha$ and $\beta$ are such that $\beta<\beta^{*}(\alpha)$ must be low enough while the probability to have $\alpha$ and $\beta$ such that $\beta \geq \beta^{*}(\alpha)$ and $\beta \geq \hat{\beta}$ must be high enough in order to observe the offer of both tournament and revenue sharing schemes to agents and to allow them to self-select.

In our framework, we consider the marginal return of effort investment equal to one under the revenue-sharing scheme. In public goods games, the effort productivity is usually higher than one, as cooperation is beneficial. To take this into account, we could change the gross payment from $\frac{v}{2} Q$ to $\frac{v}{2} Q . g$ with $g \in[1,2]$. A separating equilibrium is still achievable at the cost of an incentive constraint more restrictive than (13) but is

\footnotetext{
${ }^{21}$ The optimal $\tau$ is equal to $\tau_{\text {tour }}^{*}$.

${ }^{22}$ As the expected profit function of the principal is different from that of the previous section, we maximized the one considered here to find the optimal contract and it is shown that there is no difference between the two cases. The optimal $\tau$ is equal to $\tau_{\text {tour }}^{*}$.
} 
also compensated by an increase in the equilibrium effort level under the revenue-sharing scheme. Therefore, considering a marginal return on investment higher than one does not change the conclusions presented previously.

The robustness of our results must be verified when the nature of the alternative payment scheme to the tournament is chosen by the principal herself. Another potential model would be to consider an alternative option to the tournament as a linear combination of the tournament and the revenue-sharing schemes. Agents' utility function would become: $Z_{i}\left(e_{i}, e_{j}\right)=k V_{i}\left(e_{i}, e_{j}\right)+(1-k) U_{i}\left(e_{i}, e_{j}\right)$. After having derived equilibrium effort levels for both types of agents under this design, we found a necessary and sufficient condition for the existence of a separating equilibrium which depends on $k$. The principal settles on the optimal contract which consists of choosing $k^{*}, \tau^{*}$ and $v^{*}$. For inequity aversion degrees of type $t_{A}$ agents sufficiently high, they accept to work under the alternative organization instead of the tournament only if $k$ is small ${ }^{23}$. The structure of the alternative option is optimal because its parameters, and especially $k^{*}$, are determined by the principal. Therefore, to make the alternative payment scheme endogeneous does not change qualitatively our results. A separating equilibrium between types of agents does exist and agents' self-selection is then induced.

Our final remark concerns the length of the interactions. We analyzed one period interactions between agents to emphasize the impact of fairness preferences on incentives. We can show that the sorting improves workers' productivity even for long-term relations. In a revenue-sharing scheme, a long-term interaction may lead to a decline in cooperation. However, when all the agents are fair-minded, the cooperation might last even if interactions are repeated over many time periods. In tournaments, it is known that incentives can be weakened because of collusion which emerges between agents when prizes are fixed. If all the agents in the tournament do not dislike inequalities, this collusion might not appear.

\footnotetext{
${ }^{23}$ Due to the complexity of the function and the numerous variables, the results are not tractable analytically. We decided to report only the intuition here.
} 


\section{Conclusion}

The main finding of our study is that one particular group incentive mechanism cannot be efficient when the working population is heterogeneous in terms of social preferences such as inequity aversion. In a real company setting, multiple performance-based payment schemes are needed to insure adapted incentives for different types of agents. In terms of efficiency, when agents' degree of inequity aversion is private information, it is better to offer multiple schemes provided that people can choose where to work if the market is perfectly flexible.

People differing in their social preferences react differently when set in a competitive environment. Agents who are exclusively concerned by their own payoff are strongly and positively affected by this kind of incentives. However, inequity averse agents who dislike ex post inequality between payoffs exert a low effort level in equilibrium under the tournament. They prefer to opt out of the tournament if their advantageous and disadvantageous inequity aversion are high enough. Agents with social preferences are better off under a payment scheme which shares equally the joint output between the workers of the group. Their equilibrium effort level in the revenue-sharing scheme is higher than the free-riding equilibrium if it is common knowledge that all the agents in the revenue-sharing organization are fair-minded.

If there is no mobility cost, we show that there exists a unique and separating equilibrium when the principal offers both payment schemes, the tournament and the revenuesharing scheme, and allows agents to self-select. Selfish agents prefer to work under the tournament and inequity averse agents prefer to work under the revenue-sharing scheme if their degree of inequity aversion is high enough. The necessary and sufficient condition for this situation to be stable is that selfish workers do not want to join the revenuesharing structure. In this case, no pooling issue is sustainable in equilibrium. Besides, mono-organizational structures are not available in the sense that they are unstable. The creation of a new structure implementing the payment scheme not so far available on the market is always profitable through the attraction of one type of agents. The optimal contract for the principal is then to offer both payment schemes and to allow agents to 
self-select into these two different payment schemes whatever the proportion of fair-minded agents.

The conclusions of this paper highlight the importance of considering workers' selfselection based on social preferences heterogeneity when they have the possibility to choose their payment scheme. Indeed, a particular performance-based payment scheme is not efficient for the whole working population in terms of incentives. A business environment that allows people to select their payment scheme may induce an identification of personality types ex post. Homogeneous groups are composed and adapted incentives applied to the corresponding individuals. Self-selection of workers is then an important aspect of efficient work incentive schemes.

An extension of this study would be to differentiate agents by their skill levels. Agents' ability may have an impact on their effort decision and on their choice of payment schemes also. High-skilled agents may be more likely to prefer competition than low-skilled agents. It may be interesting to analyze if it is in everyone's interest to have homogeneous groups in terms of both abilities and social preferences. Risk aversion of agents would be another individual characteristic to consider. When agents have diverse personality types, selfselection leads to a more efficient exploitation of the differing incentives provided by variable payment schemes.

\section{APPENDIX}

Proof of Proposition 3. As $U_{i}\left(e_{i}, e_{j}\right)$ is different when $e_{i}>e_{j}$ and $e_{i}<e_{j}$, we check the conditions under which player $i$ of type $t_{A}$ does not have an incentive to deviate.

Type $t_{A}$ workers are assumed identical so, they have the same equilibrium strategy.

We consider a situation with symmetric strategies $\left(\hat{e}_{A}, \hat{e}_{A}\right)$ and we check whether agents have an interest in deviating.

- Deviation for $e_{i}>\hat{e}_{A}$ ?

The worker does not deviate if $U_{i}\left(\hat{e}_{A}, \hat{e}_{A}\right) \geq U_{i}\left(e_{i}, \hat{e}_{A}\right)$

$\Longleftrightarrow v \hat{e}_{A}-\hat{e}_{A}^{2} \geq \frac{1}{2} v\left(e_{i}+\hat{e}_{A}\right)-e_{i}^{2}-\alpha\left(e_{i}^{2}-\hat{e}_{A}^{2}\right)$

$\Longleftrightarrow \hat{e}_{A} \geq \frac{v}{2(1+\alpha)}-e_{i}$

As the equilibrium is symmetric, 
$\Longleftrightarrow \hat{e}_{A} \geq \frac{v}{4(1+\alpha)}$

It means that a worker of type $t_{A}$ does not want to deviate from the situation $\left(\hat{e}_{A}, \hat{e}_{A}\right)$ for $e_{i}>\hat{e}_{A}$ if $\hat{e}_{A}$ is such that $\hat{e}_{A} \geq \frac{v}{4(1+\alpha)}$.

We use the same method to determine if type $t_{A}$ workers have an incentive to deviate to a lower effort level.

- Deviation for $e_{i}<\hat{e}_{A}$ ?

The worker does not deviate if $U_{i}\left(\hat{e}_{A}, \hat{e}_{A}\right) \geq U_{i}\left(e_{i}, \hat{e}_{A}\right)$

$\Longleftrightarrow v \hat{e}_{A}-\hat{e}_{A}^{2} \geq \frac{1}{2} v\left(e_{i}+\hat{e}_{A}\right)-e_{i}^{2}-\beta\left(\hat{e}_{A}^{2}-e_{i}^{2}\right)$

$\Longleftrightarrow \hat{e}_{A} \leq \frac{v}{2(1-\beta)}-e_{i}$

As the equilibrium is symmetric,

$\Longleftrightarrow \hat{e}_{A} \leq \frac{v}{4(1-\beta)}$

It means that a worker of type $t_{A}$ does not want to deviate from the issue $\left(\hat{e}_{A}, \hat{e}_{A}\right)$ for $e_{i}<\hat{e}_{A}$ if $\hat{e}_{A}$ is such that $\hat{e}_{A} \leq \frac{v}{4(1-\beta)}$.

Proof of Proposition 4. Two sorts of equilibria may exist: separating (each type of agents work under a different payment scheme) and pooling (both types of agents work under the same payment scheme) equilibria. We first check whether pooling equilibria may exist.

- Suppose a situation such that both types of people work under the tournament. As we showed in the previous section, this situation is unstable because inequity averse workers have an interest in leaving the tournament for the outside option because $\rho E\left[V_{A}\left(e_{A}^{*}, e_{A}^{*}\right)\right]+(1-\rho) E\left[V_{A}\left(e_{A}^{*}, e_{S}^{*}\right)\right]<\underline{\mathrm{u}}$. Then, a pooling equilibrium under the tournament does not exist. Imagine a situation in which both personality types work in a revenue-sharing organization. As inequality (13) is verified, selfish agents prefer to leave the revenue-sharing scheme for the tournament whatever the strategy of inequity averse agents. This second situation is then not stable. Finally, suppose a situation such that both types prefer the outside option. This situation is not stable because we know from section 4.1. that selfish agents prefer to work under the tournament than to take the outside option. Consequently, no pooling equilibrium subsists if there exists an incentive compatible constraint that causes selfish agents to derive a higher expected utility under the tournament. No option (the tournament, the revenue-sharing scheme or the outside 
option) is ever accepted by both types of agents.

The second thing which must be clear is the uniqueness of the separating equilibrium.

- Suppose that selfish people work under the tournament and inequity averse ones under the outside option. We know that inequity averse agents have no interest to go to the tournament but they may be attracted by a revenue-sharing scheme. Knowing that inequality (13) is verified, they join the revenue-sharing organization and play an equilibrium strategy higher than that of the free-riding equilibrium. Suppose that selfish people choose the outside option and inequity averse people choose the revenue-sharing scheme. This separating situation is not stable because selfish workers prefer to leave the outside option to go to work under the tournament.

Consequently, selfish people working under the tournament and inequity averse ones under the revenue-sharing scheme is the unique equilibrium. Agents realize their equilibrium effort level under each payment scheme which is to realize a high effort level.

\section{References}

[1] Asheim, Geir B. and Dufwenberg, Martin, (2003). "Deductive Reasoning in Extensive games." The Economic Journal, 113, pp. 305-325.

[2] Bandiera, Oriana; Barankay, Iwan and Rasul, Imran, (2005). "Social Preferences and the Response to Incentives: Evidence from Personnel Data." Quaterly Journal of Economics, 120(3), pp. 917-962.

[3] Bartling, Björn and von Siemens, Ferdinand, (2004). "Efficiency in Team Production with Inequity Averse Agents." Working Paper.

[4] Battigalli, Pierpaolo and Siniscalchi, Marciano, (2002). "Strong Belief and Forward Induction Reasoning." Journal of Economic Theory, 106, pp. 356-391.

[5] Bellemare, Charles and Shearer, Bruce S., (2006). "Sorting, Incentives and Risk Preferences: Evidence from a Field Experiment." IZA Discussion Paper 2227.

[6] Biel, Pedro Rey, (2004). "Inequity Aversion and Team Incentives." Working Paper.

[7] Bolton, Gary E. and Ockenfels, Axel, (2000). "ERC - A Theory of Equity, Reciprocity and Competition." The American Economic Review, 90(1), pp. 166-193. 
[8] Burlando, Roberto M. and Guala, Francesco, (2005). "Heterogeneous agents in public goods experiments." Experimental Economics, 8(1), pp. 35-55.

[9] Cabrales, Antonio and Calvó-Armengol, Antoni, (2007). "Interdependent Preferences and Segregating Equilibria." University Carlos III de Madrid, Working Paper, 07-23.

[10] Charness, Gary and Rabin, Matthew, (2002). "Understanding Social Preferences with Simple Tests". The Quarterly Journal of Economics, 117(3), pp. 817-869.

[11] Cooper, Russell; Dejong, Douglas V.; Forsythe, Robert and Ross, Thomas W., (1992). "Forward induction in coordination games." Economics Letters, 40(2), pp. 167-172.

[12] Demougin, Dominique and Fluet, Claude, (2003). "Inequity Aversion in Tournaments." CIRPEE Working Paper, 03-22.

[13] Dufwenberg, Martin and Kirchsteiger, Georg, (2004). "A theory of sequential reciprocity." Games and Economic Behavior, 47, pp. 268-298.

[14] Ehrhart, Karl-Martin and Keser, Claudia, (1999). "Mobility and Cooperation: On the Run." CIRANO Scientific series, 99s-24.

[15] Engelmann, D. and Strobel, M., (2004). "Inequality Aversion, Efficiency, and Maximin Preferences in Simple Distribution Experiments." The American Economic Review, $94(4)$, pp. 857-869.

[16] Falk, Armin and Fischbacher, Urs, (2006). "A theory of reciprocity." Games and Economic Behavior, 54, pp. 293-315.

[17] Fehr, Ernst and Fischbacher, Urs, (2002). "Why Social Preferences Matter - The impact of Non-Selfish Motives on Competition, Cooperation and Incentives." Economic Journal, 112, C1-C33.

[18] Fehr, Ernst and Schmidt, Klaus M. (1999). "A Theory of Fairness, Competition, and Cooperation." The Quaterly Journal of Economics, 114(3), pp. 817-868.

[19] Fischbacher, Urs and Gächter, Simon, (2006). "Heterogeneous social preferences and the dynamics of free riding in public goods." IEW Working Paper No. 261, University of Zurich.

[20] Frank, Robert H., (1985). "Choosing the Right Pond - Human Behavior and the Quest for Status." Oxford: Oxford University Press.

[21] Gächter, Simon and Thöni, Christian, (2005). "Social learning and volontary cooperation among like-minded people." Journal of the European Economic Association, 3(2-3), pp. 303-314. 
[22] Grund, Christian and Sliwka, Dirk, (2005). "Envy and Compasion in Tournaments." Journal of Economics and Management Strategy, 14(1), pp. 187-207.

[23] Hamilton, Barton H.; Nickerson, Jack A. and Owan, Hideo, (2003). "Team Incentives and Worker Heterogeneity: An Empirical Analysis of the Impact of teams on Productivity and Participation." Journal of Political Economy, 111, pp. 465-497.

[24] Holmstrom, Bengt, (1982). "Moral Hazard in Teams." The Bell Journal of Economics, 13(2), pp. 324-340.

[25] Kohlberg, Elan and Mertens, Jean-François, (1986). "On the Strategic Stability of Equilibria." Econometrica, 54, pp. 1003-1038.

[26] Kosfeld, Michael and von Siemens, Ferdinand, (2006). "Competition, Cooperation, and Corporate Culture." Working Paper.

[27] Kräkel, Matthias, (2000). "Relative deprivation in rank-order tournaments." Labour Economics, 7, pp.385-407.

[28] Lazear, Edward P., (1989). "Pay Equality and Industrial Politics." Journal of Political Economy, $97(3)$, pp. 561-80.

[29] Lazear, Edward P., (2000). "Performance Pay and Productivity." The American Economic Review, $90(5)$, pp. 1346-1361.

[30] Ledyard, John O., (1995). "Public Goods: A survey of experimental research." In: Kagel, John and Roth, Alvin E. (Eds.), Handbook of Experimental Economics. Princeton: Princeton University Press 1995.

[31] McMaughlin, Kenneth J., (1988). "Aspects of Tournament Models: A Survey." Research in Labor Economics. JAI Press, pp. 225-256.

[32] Mui, Vai-Lam, (1995). "The Economics of Envy." Journal of Economic Behavior and Organization, 26(3), pp. 311-336.

[33] Nalbantian, Haig R. and Schotter, Andrew, (1997). "Productivity Under Group incentives: An Experimental Study." The American Economic review, 87(3), pp. 314-341.

[34] O'Dell, Carla and McAdams, Jerry L., (1987). "The Revolution in Employee Rewards." Compensation and Benefits Review, 19, pp. 68-73.

[35] Prendergast, Canice, (1999). "The Provision of Incentives in Firms." Journal of Economic Literature, $37(1), 7-63$. 
[36] Rabin, Matthew, (1993). "Incorporating Fairness into Game Theory and Economics". The American Economic Review, 83(5), pp. 1281-1302.

[37] Sobel, Joël, (2005). "Interdependent Preferences and Reciprocity." Journal of Economic Literature, XLIII, pp. 392-436.

[38] Stark, Oded, (1987). "The Design of Reward Structures in Career Games: A Relative Deprivation Approach." Economics Letters, 25(4), pp. 389-392.

[39] Tullock, Gordon, (1980). "Efficient Rent Seeking." In James M. Buchanan, Robert D. Tollison, and Gordon Tullock, eds.. Toward a Theory of the Rent Seeking Society, College Station: Texas A\&M University Press, 1980, pp. 269-282.

[40] van Damme, Eric, (1989). "Stable Equilibria and Forward Induction." Journal of Economic Theory, 48, pp. 476-496. 